Forstner, U. \& Wittmann, G. T. W. 1981. Metal pollution in the aquatic environment. Berlin: SpringerVerlag.

MacKay, D. W. 1985. Sludge dumping in the Firth of Clyde. Annual Meeting of British Association for the Advancement of Science, 26-30 August 1985.

McKie, J. C. 1983. An examination of metals in flounders (Platichthys tlexus) collected from two Scottish estuaries. Copenhagen: International Council for Exploration of the Sea, CM1983/E:39.

Topping, G. \& McIntyre, A. D. 1972. Benthic observations on a sewage sludge dumping ground. Copenhagen: International Council for Exploration of the Sea, CM1972 E:30.

Warren, L. 1977. The ecology of Capitella capitata in British waters. Jounal of the Marine Biology Association of United Kingdom 57, 151-159.

\title{
Hydrocarbons and their microbial degradation in the Firth of Forth
}

\author{
L. C. Massie, A. D. McIntosh and J. M. Davies
}

DAFS Marine Laboratory, P.O. Box 101, Victoria Road, Aberdeen AB9 8DB, Scotland, U.K.

and

\section{P. R. Mackie}

MAFF Torry Research Station, Torry, Aberdeen, Scotland, U.K.

Monitoring of hydrocarbons and assessment of their microbial degradation in the Firth of Forth is part of a larger programme undertaken by the Department of Agriculture and Fisheries for Scotland to monitor the levels of hydrocarbons in the marine environment (Massie et al. 1985a,b; 1986) around the coast of Scotland and to investigate the possible effects of oil exploration and production on fisheries. The reception terminal for the oil from the Forties field is at Grangemouth and the tanker loading facility is at Hound Point. The estuary, however, receives oil and hydrocarbons from combustion of fossil fuels from many sources around its shores, such as industrial complexes, coal-fired power station, the naval dockyard and shipping.

Initially all water and surface sediment samples obtained by water bottle and grab, respectively, are screened by UV fluorescence and the hydrocarbons present expressed as crude oil or diesel "fluorescence equivalents". Selected samples are then examined in greater detail by capillary gas chromatography (aliphatic hydrocarbons) and gas chromatography/mass spectrometry (aryl hydrocarbons). The potential of microbial populations in water and/or sediments to degrade the hydrocarbons are determined using $1-^{14} \mathrm{C}$ naphthalene, $1-^{14} \mathrm{C}$ hexadecane and $7,10^{14} \mathrm{C}$ benzo(a)pyrene.

There was a strong gradient of hydrocarbon concentrations in the sediments of the estuary. The stations at Bridges and Hound Point were most heavily contaminated with the stations becoming less contaminated approaching the sea. The 3- and 4-ring aromatic compounds predominated in the aromatic fraction, but all sediments examined showed an accumulation of 5- and 6-ring compound (similar to those seen in North Sea sediments remote from oil-related activities). The relative composition and the ratio of benzo(e)pyrene to benzo(a)pyrene 
indicated combustion products (from industrial complexes, domestic fires and vehicle exhausts) as their major source but the smaller 2- and 3-ring compounds present also indicated some input of mainly fuel oils to the sediments.

Comparison with the findings of other workers in similar estuaries and coastal areas is very difficult because of varying analytical procedures and the choice of compounds quantified, but Thomson \& Eglinton (1978) and Eglinton et al. (1975) have found $9 \mu \mathrm{g} \mathrm{g}^{-1}$ and $140 \mu \mathrm{gg}^{-1} 3-5$ ring PAH (polyaromatic hydrocarbons) in sediments from the industrialised Severn Estuary in southwest England compared to $8.4 \mu \mathrm{g} \mathrm{g}^{-1}$ and $33.4 \mu \mathrm{g} \mathrm{g}^{-1} 2-6$ ring PAH found in the Forth.

In sediments the rate of mineralisation of $1{ }^{14} \mathrm{C}$ hexadecane was low and that of $7,10^{14} \mathrm{C}$ benzo(a)pyrene was negligible. The rate of mineralisation of $1-{ }^{14} \mathrm{C}$ naphthalene was also low although in 1984 it had increased somewhat. Experience (Massie \& Davies 1987) has shown that hydrocarbon-degrading heterotrophs respond quickly to mineralise the lower molecular weight hydrocarbons, but that the rate decreases when these compounds become a small part of the total organic input. The larger molecules for which the heterotrophs showed no potential for degradation will accumulate in the sediments.

In the water column there was a gradient of decreasing concentrations of hydrocarbons from the inner estuary out to the sea. In the aromatic fractions the GC-MS analysis showed the presence mainly of 3- and 4-ring aromatic compounds and only trace amounts of the 5- and 6-ring compounds in the water column. As for sediments, their source was found to be combustion products and oil. The rate of mineralisation and assimilation of $1-{ }^{14} \mathrm{C}$ naphthalene in the water column showed that the heterotrophs have the potential to degrade the smaller hydrocarbon molecules at high rates.

\section{References}

Eglinton, G., Simoneit, B. R. T. \& Zoro, J. A. 1975. The recognition of organic pollutants in aquatic sediments. Proceedings of the Royal Society of London B189, 415-552.

Massie, L. C., Ward, A. P., Davies J. M. \& Mackie, P. R. 1985a. The effects of oil exploration and production in the northern North Sea: Part 1 -The levels of hydrocarbons in water and sediments in selected areas 1978-1981. Marine Environmental Research 15, 165-213.

-1985 b. The effects of oil exploration and production in the northern North Sea: Part 2-Microbial biodegradation of hydrocarbons in water and sediments, 1978-1981. Marine Environmental Research 15, 235-262.

—, McIntosh, A. D. \& Davies, J. M. 1986. A survey of hydrocarbon levels and hiodegradation rates in selected areas of the northern North Sea, 1983-1985. Copenhagen: International Council for Exploration of the Sea, CMI986/E:5.

- \& Davies, J. M. 1987. Environmental surveys to study the recovery of marine sediments contaminated by oiled drill cuttings. In Microbial problems in the offshore oil industry, eds. Hill, E. C., Shennan, J. L. \& Watkinson, R. J., pp. 125-145. Chichester: John Wiley.

Thompson, S. \& Eglinton, G. 1978. Composition and sources of pollutant hydrocarbons in the Severn Estuary. Marine Pollution Bulletin 9, 133-136. 